\title{
Comparison of the Socioeconomic Factors and Diagnostic Test between Pulmonary Tuberculosis (PTB) and Extrapulmonary Tuberculosis (ETB) in Boyacá (Colombia), in 2015
}

\section{Comparación de factores socioeconómicos y diagnósticos relacionados con tuberculosis pulmonar y extrapulmonar en Boyacá durante 2015}

\footnotetext{
Yardany Rafael Méndez Fandiño ${ }^{1}$

Universidad Pedagógica y Tecnológica de Colombia,

Colombia

Edgar Yaset Caicedo Ochoa

Universidad Pedagógica y Tecnológica de Colombia,

Colombia

Jorge Andrés Urrutia Gómez

Universidad Pedagógica y Tecnológica de Colombia,

Colombia

Héctor Fabio Cortés Motta

Universidad Pedagógica y Tecnológica de Colombia,

Colombia

Nasly Consuelo Ávila Espitia

Universidad Pedagógica y Tecnológica de Colombia,

Colombia

Gloria Camila Álvarez Gallego

Universidad Pedagógica y Tecnológica de Colombia,

Colombia
}

1 Internal Medicine Specialist, Universidad del Rosario, Colombia. Director of the Bacterial Resistance Analysis Group of Boyacá. Head of the Department of Internal Medicine, Universidad Pedagógica y Tecnológica de Colombia, Tunja, Colombia.

How to cite: Méndez Fandiño YR, Caicedo Ochoa EY, Urrutia Gómez JA, Cortés Motta HF, Ávila Espitia NC, Álvarez Gallego GC. Comparison of the socioeconomic factors and diagnostic test between pulmonary tuberculosis (PTB) and extrapulmonary tuberculosis (ETB) in Boyacá (Colombia), in 2015. Univ. Med. 2018;59(4). doi: https://doi.org/ 10.11144/Javeriana.umed59-3.cfsd

\begin{abstract}
Introduction: Tuberculosis (TB) is an infectious disease caused by Micobacterium tuberculosis. It usually affects the lungs, but can also affect other systems. The objective of this study was to make a comparison of the socioeconomic factors and diagnostic test between pulmonary tuberculosis (PTB) and extrapulmonary tuberculosis (ETB) in Boyacá (Colombia) in 2015. Methods: A retrospective analytical observational study was conducted on the data provided by the Boyacá Department of Health about the TB possible cases reported in the SIVIGILA system. 103 TB possible cases were selected, then these cases were divided in accordance with the TB type in two groups, PTB and ETB. Duplicated data were excluded. Results: The highest number of isolates was of PTB. With regard to the ETB group, they required more medical attention, and the most frequent isolates were meningeal, pleural and osteoarticular. In addition, undernourishment was related with PTB. Conclusion: The
\end{abstract}


creation of new social, cultural and economic approaches against the TB dissemination becomes a primary point for the control of this disease.

Keywords

tuberculosis; risk factors; diagnosis.

\section{RESUMEN}

Introducción: la tuberculosis (TB) hace parte del grupo de enfermedades infectocontagiosas, producida por Mycobacterium tuberculosis. Aunque se encuentra principalmente en los pulmones, puede afectar otros órganos. Objetivo: comparar los factores socioeconómicos y los métodos diagnósticos relacionados con la tuberculosis pulmonar (tuberculosis pulmonar) y extrapulmonar (tuberculosis extrapulmonar) en el departamento de Boyacá durante 2015. Materiales y métodos: se realizó un estudio observacional de tipo retrospectivo. Contó con los datos proporcionados por la Secretaría de Salud de Boyacá ante los eventos de notificación obligatoria de posibles casos de TB reportados en el sistema Sivigila. Se seleccionaron 103 eventos reportados de diagnóstico de TB en el departamento de Boyacá, Colombia; luego se dividieron en grupos de análisis según el tipo de TB, excluyendo los datos duplicados. Resultados: el mayor número de aislamientos fue de tuberculosis pulmonar. En cuanto a los pacientes con tuberculosis extrapulmonar, requirieron más atención médica, y los aislamientos más frecuentes fueron, meníngeo, pleural y osteoarticular; adicionalmente, la desnutrición se asoció con la presentación de tuberculosis pulmonar. Conclusión: la generación de nuevos abordajes sociales, culturales y económicos frente al comportamiento de la TB es primordial para controlar esta enfermedad.

Palabras clave

tuberculosis; tuberculosis miliar; diagnóstico.

\section{Introduction}

Tuberculosis is part of the group of infectious and contagious diseases produced by Mycobacterium tuberculosis (1); it is found mainly in the lungs; however, it can affect other organs (2). This pathology is under discrimination and stigmatization due to society's intrinsic factors; consequently, patients underestimate the pathology by not going to the medical service or not adhering to the treatment. Currently, it is a public health problem, because it is a chronic disease with lasting health effects; in addition, its complications cause disability and, to a lesser extent, death (1).

Although there is an adequate coverage in terms of diagnosis and treatment of this entity, various risk factors determine its presentation, among which are individual aspects, such as immunosuppression, concomitant diseases (diabetes, HIV/AIDS or alcoholism), and time and frequency of exposure to the tuberculosis bacillus; there are also socioeconomic factors, such as overcrowding, inadequate ventilation in closed environments, undernourishment and a poor quality of life; these conditions are prevalent in the population of Boyacá, which reiterates the great importance of knowing the epidemiology of this pathology in the department of Boyacá, since it is essential to know the relationship of the prevalence of tuberculosis with the variables present in the population of this region (1).

In $90 \%$ of cases, after infection, the mycobacteria remain dormant for the rest of the individual's lifetime; but around 10\% of infected people develop the active form of contagious tuberculosis. This $90 \%$ refers to more than 2 billion people in the world (3). According to the Weekly Epidemiological Bulletin Number $52,12,918$ cases of all forms of tuberculosis were reported in Colombia in 2015. Of these, $81.4 \%$ corresponded to the pulmonary form, and $18.4 \%$ corresponded to extrapulmonary forms. Significantly, 439 cases were meningeal, which revealed a $2.0 \%$ increase in comparison with the record of the immediately preceding year for the same epidemiological week (4).

It remains necessary to clarify the reason why, although the global prevalence of tuberculosis has diminished remarkably, the pathology is still present, despite the monitoring carried out by the responsible entities. Up to now, eradication has not been achieved, understood as no case of the disease, as a result of efforts by health entities, where control measures are no longer necessary in order to prevent the resurgence and transmission of the disease (5).

It is relevant to mention aspects such as the inadequate application of established protocols for the treatment of tuberculosis or seropositive HIV cases coinfected with the bacillus in treatment for it, but without antiretroviral treatment, which could be related to the multidrug resistance of the bacillus, currently studied, since it limits the effective treatment 
of affected patients and thus lengthens the path towards the new objective of the World Health Organization (WHO) Stop TB Strategy, which is the elimination of tuberculosis by 2050 . Elimination means no cases of the disease in a specific geographical area, as a result of efforts made by health entities, where control measures are necessary to prevent the resurgence and transmission of the disease; however, in terms of tuberculosis, elimination means less than one case of smear-positive active TB in one million inhabitants per year $(5,6)$.

Despite the measures taken by health entities in Colombia to control tuberculosis, the monitoring by the National Health System could be limited, in terms of not establishing the relationship between the variables found in the information collected and the frequency measures of the illness. Consequently, the objective of the article is to compare the socioeconomic factors and the diagnostic methods related to pulmonary and extrapulmonary tuberculosis in the department of Boyacá during 2015, which are included within the guidelines of mandatory reporting of cases of tuberculosis.

\section{Methodology}

Design. A retrospective observational study was conducted. The study included the data provided by the Department of Health of Boyacá regarding the events of mandatory reporting of possible cases of tuberculosis of the Public Health Surveillance System (1) of the National Institute of Health. The research group analyzed the reports of the 2015 epidemiological report until Week 44; in addition, the information was requested and analyzed in November 2015.

Sample. It was a non-probabilistic type. The reported events of tuberculosis in the department of Boyacá, Colombia, were selected. Then they were divided into groups for analysis according to the type of tuberculosis diagnosed, pulmonary or extrapulmonary. Duplicate cases were excluded.
Information collected. The variables taken into account of the data collected by the Public Health System were:

Characteristics of the report: epidemiological week and municipality of the department where it was notified.

Demographic: gender, age (including age group such as patients under 18 years of age, patients between the ages of 18 and 60, patients over 60 years of age), nutritional status of the patient, area of origin, regime to which the patient is affiliated, indigenous people.

Characteristics of the event: time elapsed from the presentation of the symptoms to consultation, initial classification of the case, hospitalization, mortality, presence of scar of the Bacillus Calmette-Guérin (BCG) vaccine, health personnel, previous diagnosis of HIV, HIV test, coinfection.

Characteristics of the diagnosis and treatment: start of treatment, bacilloscopy, culture, histopathology and molecular testing.

Diagnostic aids: clinical aids, aids for the epidemiological link, radiological aids, aids with adenosine deaminase and tuberculin.

Statistical analysis. It was carried out with the Stata 12 program. Discrete variables were described by relative and absolute frequency; meanwhile, the continuous variables with average and standard deviation. The comparison between the discrete variables was made by Fisher's exact test, and between the continuous variables by Student's T test, and depending on whether it did not present a normal distribution, the Mann-Whittney $U$ test was used. A p < 0.05 was taken into account as a statistically significant value.

\section{Results}

\section{Description of the picture}

103 reports were obtained during the followup period. According to the epidemiological week, the report peaks occurred in Week 12, with 7 cases; Weeks 17 and 37, each with 5 cases reported (Figure 1). Figure 2 shows the 
municipalities where the isolates were made, where the municipality of Puerto Boyacá had $18.45 \%$ of reported cases; followed by Sogamoso, with $9.71 \%$, and Tunja, with $8.74 \%$ (Figure 2).

\section{Figure 1}

Frequency of tuberculosis isolates in 2015 until Epidemiological Week 44

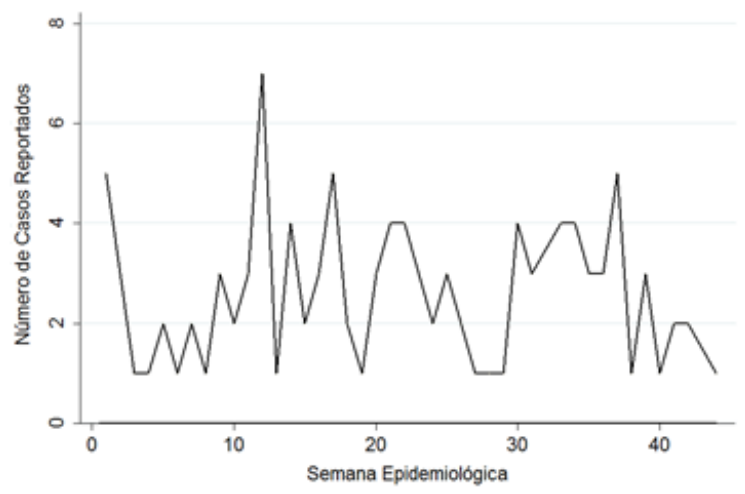

Figure 2

Municipalities of Boyacá where tuberculosis cases were reported (the intensity of the color is due to the number of cases reported in the municipality)

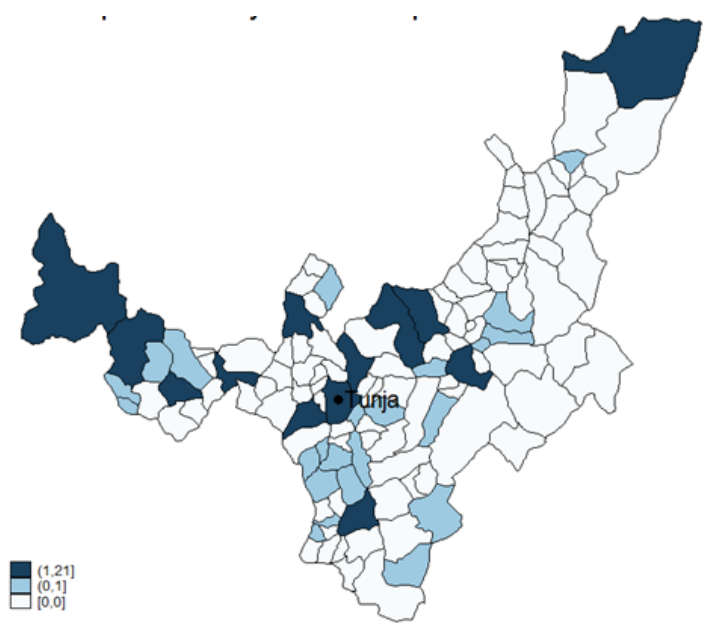

Of the 103 isolates, $66.99 \%$ were of pulmonary tuberculosis and $33.01 \%$ were of extrapulmonary tuberculosis. Of the extrapulmonary cases, $32.35 \%$ were meningeal; $29.41 \%$, pleural, and $11.76 \%$, osteoarticular (Figure 3).
Figure 3

Location of the extrapulmonary tuberculosis isolates

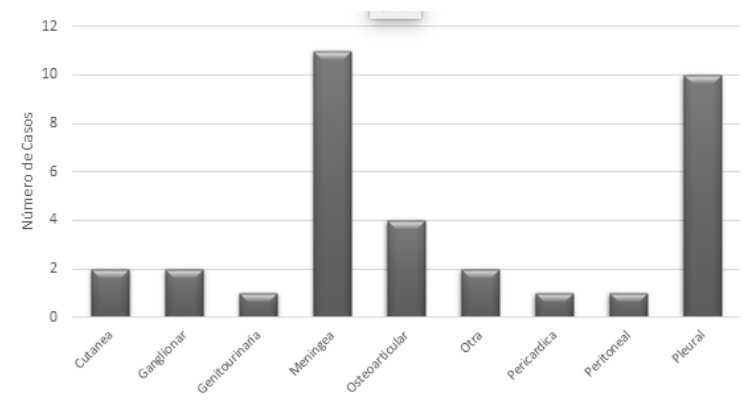

There were no significant differences within the demographic characteristics of the patients. However, regarding the nutritional status, $20.29 \%$ of patients with pulmonary tuberculosis were undernourished, a much higher prevalence than $2.94 \%$ of extrapulmonary tuberculosis $(\mathrm{p}=0.01)$. According to the time from the presentation of symptoms to medical consultation, pulmonary tuberculosis presented more chronically, with an average of 81.39 \pm 143.16 days, compared with extrapulmonary tuberculosis, of $37.82 \pm 55.45$ days $(\mathrm{p}=0.01)$.

Most of the pulmonary tuberculosis diagnoses were clinical, $82.35 \%$ of cases, and pulmonary tuberculosis, by laboratory tests, $89.86 \%$ of cases. Both groups, compared to each other, were statistically different $(\mathrm{p}<0.001)$. On the other hand, regarding the interventions to patients with extrapulmonary tuberculosis, $76.47 \%$ were hospitalized, being higher than a possible home treatment of patients with pulmonary tuberculosis, of whom $10.14 \%$ were hospitalized, the difference being statistically significant $(p<0.001)$, as shown in Table 1. 
Table 1

Demographic characteristics in percentages (the numbers in parentheses represent the cases)

\begin{tabular}{|c|c|c|c|}
\hline Variables & $\begin{array}{l}\text { Pulmonary } \\
(\mathrm{n}=69)\end{array}$ & $\begin{array}{l}\text { Extrapulmonary } \\
(n=34[\%])\end{array}$ & $p$ \\
\hline Age & $\begin{array}{l}52.44 \pm \\
20.47 \\
\end{array}$ & $59.67 \pm 19.71$ & 0.09 \\
\hline $\begin{array}{l}\text { Under } 18 \text { years of } \\
\text { age }\end{array}$ & $5.8(4)$ & $2.94(1)$ & 1.00 \\
\hline $19-60$ year's old & $55.07(38)$ & $38.24(13)$ & 0.14 \\
\hline Older than 60 & $39.13(27)$ & $58.82(20)$ & 0.09 \\
\hline \multicolumn{4}{|l|}{ Sex } \\
\hline Males & $50.75(35)$ & $58.82(20)$ & 0.53 \\
\hline \multicolumn{4}{|l|}{ Body weight } \\
\hline Obesity & $2.9(2)$ & $11.76(4)$ & 0.09 \\
\hline Normal & $76.81(53)$ & $85.29(29)$ & 0.43 \\
\hline Undernourishment & $20.29(14)$ & $2.94(1)$ & 0.01 \\
\hline \multicolumn{4}{|c|}{ Area where it occurred } \\
\hline Municipal capital & $52.17(36)$ & $50(17)$ & 1.00 \\
\hline Populated center & $17.39(12)$ & $20.59(7)$ & 0.78 \\
\hline Scattered Rural & $30.43(21)$ & $29.41(10)$ & 1.00 \\
\hline \multicolumn{4}{|l|}{ Regime } \\
\hline Contributory & $36.23(25)$ & $41.18(14)$ & 0.66 \\
\hline Subsidized & $57.97(40)$ & $50.00(17)$ & 0.52 \\
\hline Other & $1.44(1)$ & $5.88(2)$ & 0.68 \\
\hline Indigenous & $4.34(3)$ & $2.94(1)$ & 1.00 \\
\hline $\begin{array}{l}\text { Time of } \\
\text { presentation of } \\
\text { symptoms }\end{array}$ & $\begin{array}{l}81.39 \pm \\
143.16\end{array}$ & $37.82 \pm 55.45$ & 0.01 \\
\hline \multicolumn{4}{|l|}{ Initial classification } \\
\hline $\begin{array}{l}\text { Clinically } \\
\text { confirmed }\end{array}$ & $10.14(7)$ & $82.35(28)$ & $<0.001$ \\
\hline $\begin{array}{l}\text { Confirmed by } \\
\text { laboratory tests }\end{array}$ & $89.86(62)$ & $17.65(6)$ & $<0.001$ \\
\hline Hospitalized & $39.13(27)$ & $76.47(26)$ & $<0.001$ \\
\hline Mortality & $10.14(7)$ & $11.76(4)$ & 1.00 \\
\hline
\end{tabular}

Regarding the conditions at the time of diagnosis, BCG vaccination scar was more prevalent in patients with pulmonary tuberculosis $(49.28 \%$ vs. $26.47 \%, p=0.03)$. There were no differences in the patients with previous HIV, and the test was performed in both groups. We took 75 bacilloscopies, of which only $32 \%$ (24) were negative; the rest were positive. Of the cultures requested for cases of pulmonary tuberculosis, only 9 were positive; whereas of the extrapulmonary cases, only one was positive. Among the diagnostic aids, adenosine deaminase was used in patients with extrapulmonary tuberculosis $(29.7 \%)$; on the other hand, the pulmonary tuberculosis group had no case studied with this laboratory method. There were no significant differences among the other parameters (Table 2).
Table 2

Variables of the diagnosis and treatment of patients with pulmonary or extrapulmonary tuberculosis

\begin{tabular}{|l|l|l|l|}
\hline Variables & $\begin{array}{l}\text { Pulmonary } \\
(\mathrm{n}=69)\end{array}$ & $\begin{array}{l}\text { Extrapulmonary } \\
(\mathrm{n}=34)\end{array}$ & $\mathrm{p}$ \\
\hline \multicolumn{4}{|l|}{ Classification of the Admission } \\
\hline New & $\begin{array}{l}89.86 \\
(62)\end{array}$ & $100(34)$ & 0.09 \\
\hline Relapse & $4.35(3)$ & 0.00 & 1.00 \\
\hline Failure & $5.79(4)$ & 0.00 & 1.00 \\
\hline Vaccine scar & $\begin{array}{l}49.28 \\
(34)\end{array}$ & $26.47(9)$ & 0.03 \\
\hline Health worker & $2.90(2)$ & 0.00 & 1.00 \\
\hline Previous HIV & $5.80(4)$ & $11.76(4)$ & 0.43 \\
\hline HIV test & $\begin{array}{l}71.01 \\
(49)\end{array}$ & $55.88(19)$ & 0.18 \\
\hline Coinfection & $5.80(4)$ & $11.76(4)$ & 0.43 \\
\hline $\begin{array}{l}\text { Start of } \\
\text { treatment }\end{array}$ & $\begin{array}{l}86.96 \\
(60)\end{array}$ & $91.18(31)$ & 0.74 \\
\hline Bacilloscopy & $\begin{array}{l}89.86 \\
(62)\end{array}$ & $38.24(13)$ & $<0.001$ \\
\hline Culture & $\begin{array}{l}43.48 \\
(30)\end{array}$ & $35.29(12)$ & 0.52 \\
\hline Histopathology & $8.70(6)$ & $17.65(6)$ & 0.2 \\
\hline Molecular test & $8.70(6)$ & $14.71(5)$ & 0.49 \\
\hline Diagnostic Aids & $\begin{array}{l}82.61 \\
(57)\end{array}$ & $79.41(27)$ & 0.78 \\
\hline Clinical aid & $\begin{array}{l}14.49 \\
(10)\end{array}$ & $11.76(4)$ & 1.00 \\
\hline $\begin{array}{l}\text { Epidemiological } \\
\text { link }\end{array}$ & $\begin{array}{l}50.72 \\
(35)\end{array}$ & $32.35(11)$ & 0.09 \\
\hline Radiology & 0.00 & $29.41(10)$ & $<0.001$ \\
\hline $\begin{array}{l}\text { Adenosine } \\
\text { deaminase }\end{array}$ & \begin{tabular}{l} 
Tuberculin \\
\hline T.70 (6)
\end{tabular} & $5.88(2)$ & 1.00 \\
\hline
\end{tabular}

\section{Discussion}

In our study, the highest number of isolates was of pulmonary tuberculosis, with $66.9 \%$. The three municipalities with the highest number of tuberculosis cases were Puerto Boyacá, Sogamoso and Tunja. Extrapulmonary tuberculosis was the one that required more attention in terms of care, and the most frequent isolates were, in descending order, meningeal, pleural and osteoarticular.

When comparing the behavior of tuberculosis in the years 2013 (7) and 2014 (8), until Week 44, we found that there were 93 cases of tuberculosis in Boyacá in 2014. Of these, 68 of pulmonary and 25 of extrapulmonary tuberculosis, with a higher number of cases in Week 36 (6 cases) and Week 33 (5 cases). In 2013, there were 120 cases of tuberculosis, 92 of pulmonary tuberculosis and 28 of extrapulmonary tuberculosis. The weeks with the highest number of cases were Weeks 37 (9 
cases), 39 and 9 ( 7 cases) and 16 (6 cases). These data show a clear decrease in cases of pulmonary tuberculosis and an increase in extrapulmonary tuberculosis with respect to the data of our study.

In a retrospective study conducted by Sunnetcioglu et al. (9) with 411 patients, it was found that the number of cases of pulmonary tuberculosis $(49.4 \%)$ and extrapulmonary tuberculosis $(50.6 \%)$ were similar, and that the highest number of cases corresponded to adult patients (21-60 years). The BCG vaccine scar was predominant in extrapulmonary tuberculosis; while the most used diagnostic aid for pulmonary tuberculosis was bacilloscopy; biopsy was the most used for extrapulmonary tuberculosis.

The first three sites with extrapulmonary tuberculosis isolates were lymph nodes, pleura and peritoneum. Another study conducted in 427 patients in Turkey (10) showed that the ages of the patients who were diagnosed with tuberculosis were different to those described in our study $(39.4 \pm 17.6$ for extrapulmonary tuberculosis, and $39.2 \pm 17.1$ for pulmonary tuberculosis, whereas in our study they were $59.67 \pm 19.71$ and $52.44 \pm 20.47$, respectively), and in Boyacá the majority of cases occurred in the older population. The first three sites with extrapulmonary tuberculosis isolates were lymph nodes, pleural and cervical. In this study, only $27.9 \%$ of bacilloscopies were positive. A study conducted in 474 patients in Nepal (11) found a higher number of cases of pulmonary tuberculosis (244) vs. extrapulmonary tuberculosis (230). The first three sites with extrapulmonary tuberculosis isolates were lymph nodes, osteoarticular and meningeal.

In our study we found that $20.29 \%$ of patients with pulmonary tuberculosis were undernourished, and although there is no relationship with the data obtained, it has been indicated that factors such as undernourishment, lack of food, poverty, low income and geographical conditions can generate a higher incidence of cases of tuberculosis (12). According to the National Survey of the Nutritional Situation of Colombia 2010 (13), food insecurity was present in greater percentages in levels
1 and 2 (60.1\% and 45.7\%, respectively) of SISBEN (Spanish acronym for System for Selecting Beneficiaries of Social Programs). The percentage of food insecurity in Boyacá was $43.6 \%$. It should be noted that $74 \%$ of the inhabitants of urban centers such as Puerto Boyacá are between these two SISBEN levels (14). It is also important to mention that in 2010 the incidence of poverty and extreme poverty in the department of Boyacá was $46.6 \%$ and $19.1 \%$, respectively, according to the Mission for the Connection of the Series of Employment, Poverty and Inequality 2002-2010 (15). Finally, according to the general census conducted by the National Administrative Department of Statistics in 2005, the unsatisfied basic needs in Boyacá were $30.8 \%-14.1 \%$ in the municipal capitals and $49 \%$ in the rest of the territorial organization-(16).

It is of vital importance to include these data in future research to elucidate whether these factors may affect the incidence of tuberculosis in the department of Boyacá; it is also necessary to look for the possibility of cases of multidrug-resistant tuberculosis (MDRTB) and extensively drug-resistant tuberculosis (XDR-TB) cases. According to the latest WHO TB report of 2015 (17), the rate of MDR-TB has increased, without having made the necessary diagnosis to classify them as such. Only 123,000 cases of MDR-TB have been detected in 2014, compared with the estimate of 300,000 possible cases; in addition, in the group of patients with MDR-TB, it is estimated that $9.7 \%$ have XDRTB.

In the case of Colombia, 187 cases of MDRTB were detected in 2014, while the WHO estimated 360 possible cases for the same period. This situation can generate relapses that can endanger the lives of patients, and higher costs for the health system for the care of these patients.

In addition to this, we must emphasize that this study is the first of its kind in Colombia, and that from its findings new studies can be generated. Nevertheless, it must be taken into account that there may be biases in the diagnosis of extrapulmonary tuberculosis, given that the 
sensitivity and specificity of the diagnostic tool used in each case vary according to the type of sample. In addition, the tests used as culture are affected by various technical and logistical difficulties that decrease its extrapulmonary precision $(18,19)$.

\section{Conclusion}

New epidemiological approaches regarding the behavior of tuberculosis are essential for the control of this disease, and these should not only focus on the clinical aspects, but also on the social, cultural and economic aspects, to counteract the economic, social, clinical and epidemiological consequences of tuberculosis in the population. It is imperative to conduct future screening to elucidate the progress of MDR-TB and XDR-TB in our country, in order to have new information that will allow us to direct future strategies for the management and eradication of tuberculosis.

As our results show, the current picture of the management of tuberculosis is not complete, because although the therapeutic and diagnostic management is adequate, we have not considered essential elements, such as external risk factors, which can lead to an increased risk of contracting the disease (for example, poverty in the vulnerable population, which has not been reversed by State policies). It is necessary that the different entities of the State take action in order to improve the quality of life of populations, ensuring the elimination of these risk factors that are not only associated with risks of contracting tuberculosis, but many other diseases. In addition, it is clear that if we do this we will not only improve the health of the population, but there will also be more personal and collective development, improving the productivity and quality of life, and achieving lower costs for the health system.

\section{References}

1. Ortblad K, Salomon J, Bärnighausen

T, Atun R. Stopping tuberculosis: A biosocial model for sustainable development. Lancet. 2015;386(10010):2354-62.

2. Chinsembu K. Tuberculosis and nature's pharmacy of putative antituberculosis agents. Acta Tropica. 2016;153:46-56.

3. Norton BL, Holland DP. Current management options for latent tuberculosis: A review. Infect Drug Resist. 2012;5:163-73. doi: https://doi. org/10.2147/IDR.S29180

4. Dirección de Vigilancia y Análisis del Riesgo en Salud Pública-Instituto Nacional de Salud. Boletín Epidemiológico Semanal [internet]. 2015 [cited 2016 May 8];(52). Available from: http://www.ins.gov.co/boletin-ep idemiologico/Boletn\%20Epidemiolgico 12015\%20Boletin\%20epidemiologico \%20Semana\%2052.pdf.

5. Wejse C. Tuberculosis elimination in the post millennium development goals era. Int J Infect Dis. 2015;32:152-5.

6. Naciones Unidas. Objetivos de desarrollo del milenio 2013 [Internet]. Nueva York: Naciones Unidas; 2013 [cited 2016 May 13]. Available from: http://www.un.org/es/millenniu mgoals/pdf/mdg-report-2013-spanish.p df.

7. Dirección Técnica de Salud Pública de la Gobernación de Boyacá. Boletín Epidemiológico Boyacá [internet]. 2013 [cited 2016 Jun 17];(44). Available from: http://www.boyaca.gov.co/SecSa lud/direcciones/dirección-de-salud-pú blica/vigilancia-salud-publica/boletín-e pidemiológico

8. Dirección Técnica de Salud Pública de la Gobernación de Boyacá. Boletín Epidemiológico Boyacá [internet]. 2014 [cited 2016 Jun 17];(44). Available 
from: http://www.boyaca.gov.co/SecSa lud/direcciones/dirección-de-salud-pú

blica/vigilancia-salud-publica/boletín-e pidemiológico

9. Sunnetcioglu A, Sunnetcioglu M, Binici I, Baran AI, Karahocagil MK, Saydan MR. Comparative analysis of pulmonary and extrapulmonary tuberculosis of 411 cases. Ann Clin Microbiol Antimicrob [internet]. 2015 [cited 2016 Jan 26];14(1). Available from: http://www.ann-clinmicrob.com/ content $/ 14 / 1 / 34$.

10. Ates Guler S, Bozkus F, Inci MF, Kokoglu OF, Ucmak H, Ozden $\mathrm{S}$, et al. Evaluation of pulmonary and extrapulmonary tuberculosis in immunocompetent adults: A retrospective case series analysis. Med Princ Pract. 2015;24(1):75-9.

11. Sreeramareddy CT, Panduru KV, Verma SC, Joshi HS, Bates MN. Comparison of pulmonary and extrapulmonary tuberculosis in Nepala hospital-based retrospective study. BMC Infect Dis. 2008;8(1):8.

12. San Pedro A, Oliveira RM de. Tuberculose e indicadores socioeconômicos: revisão sistemática da literatura. Rev Panam Salud Publica. 2013;33(4):294-301.

13. Ministerio de la Protección Social. Encuesta Nacional de la Situación Nutricional en Colombia 2010 [internet]. 2011 [cited 2016 Jun 1]. Available from: http://www.icbf.gov.co/portal/pa ge/portal/PortalICBF/Bienestar/ENSI N1/ENSIN2010/LibroENSIN2010.pdf 14. Ministerio de Salud y Protección Social. Cobertura del régimen subsidiado Colombia año 2013 [internet]. 2014 [cited 2016 Jun 1]. Available from: https://www.minsalud.gov.co/sal ud/Paginas/CoberturasdelR\%C3\%A9g imenSubsidiado.aspx
15. Departamento Administrativo Nacional de Estadística, Departamento Nacional de Planeación. Misión para el Empalme de las Series de Empleo, Pobreza y Desigualdad (Mesep) [Internet]. 2012. [cited 2016 Jun 1]. Available from: http://www.dane.gov.co/files/not icias/Pobreza_nuevametodologia.pdf

16. Departamento Administrativo Nacional de Estadística (DANE). Necesidades básicas insatisfechas NBI- [Internet]. [cited 2016 Jun 1]. Available from: http://www.dane.gov.c o/index.php/estadisticas-sociales/neces idades-basicas-insatisfechas-nbi

17. Organización mundial de la salud. Global Tuberculosis Report 2015. [internet]. Geneva: World Health Organization; 2015. [cited 2016 Jun 1]. Available from: http://www.who.int/tb/ publications/global_report/en/

18. Norbis L, Alagna R, Tortoli E, Codecasa LR, Migliori GB, Cirillo DM. Challenges and perspectives in the diagnosis of extrapulmonary tuberculosis. Expert Rev Anti Infect Ther. 2014;12(5):633-47.

19. Ketata W, Rekik WK, Ayadi $\mathrm{H}$, Kammoun S. [Extrapulmonary tuberculosis]. Rev Pneumol Clin. 2015;71(2-3):83-92. 